International Journal of Child, Youth and Family Studies (2015) 6(4.1): 662-679

\title{
HOME ENVIRONMENT FACTORS AND ECD EXPOSURE PREDICT SCHOOL ENTRY AND GRADE PROGRESSION: A STUDY FROM A PERI-URBAN COMMUNITY IN CENTRAL UGANDA, AFRICA
}

\author{
Jolly P. Tumuhairwe Nyeko, Alan Pence, and Gordon E. Barnes
}

\begin{abstract}
This retrospective study of 535 households with 8-year-old children focuses on factors that can influence age-appropriate school entry and subsequent grade-level progression. The households included in this research are from a peri-urban community near Kampala, Uganda. Data were collected mainly from primary caregivers. The study examined the influence of family variables, home environment, stressful life events, and exposure to early childhood development (ECD) services on both age at school entry and educational grade level. Given the relative lack of African studies of this size and nature, descriptive and correlational analyses, as well as a regression analyses, are included in the findings. From the regression analyses, three major findings emerge. First, family structure (intact vs. other) and educational level of the caregiver are important variables in predicting children's enrolment in ECD, age of entry into school, and grade level in school. Second, whether the child attended ECD or not, the child's age at ECD enrolment, and the type of ECD attended are significantly related to school attendance, that is, if currently in or out of school and grade level achieved in school. Third, stressful life events in the household are significantly related to the grade-level progression of children in school.
\end{abstract}

Keywords: home environment, ECD exposure, school entry

Jolly P. Tumuhairwe Nyeko (PhD) is the Chief Executive Officer of Action For Children, Plot 110, Lutaaya Road, P.O. Box 25417, Kampala, Uganda. E-mail: jnyeko@yahoo.com

Alan Pence (PhD) is a Professor in the School of Child and Youth Care, University of Victoria, P. O. Box 1700, STN CSC, Victoria, BC V8W 2Y2, Canada. E-mail: apence@uvic.ca

Gordon E. Barnes (PhD) is a Professor Emeritus in the School of Child and Youth Care, and a Scientist Emeritus at the Centre for Addiction Research of BC, P. O. Box 1700, STN CSC, Victoria, BC V8W 2Y2, Canada. E-mail: gbarnes@uvic.ca 
International Journal of Child, Youth and Family Studies (2015) 6(4.1): 662-679

Children's entry into school at appropriate ages and their successful progression through the primary grades are strong predictors of later life opportunities and successes, and while this finding has been documented most consistently in minority (developed) world settings, there is mounting evidence that this is also the case in the majority (developing) world (Arnold, Bartlett, Gowan, \& Merali, 2006; Grantham-McGregor et al., 2007; Malmberg, Mwaura, \& Sylva, 2011; Martinez, Naudeau, \& Pereira, 2012; Njenga \& Kabiru, 2001; Richter, Foster, \& Sherr, 2006; Walker et al., 2007).

Children in resource-constrained communities in Africa are growing up with limited opportunities for education and other basic necessities like health services and adequate nutrition (Aidoo, 2008; Grantham-McGregor et al., 2007; Irwin, Adams, \& Winter, 2009). The care, development, and education of these children is highly dependent on their primary caregivers and is greatly influenced by community factors, such as the social, spiritual, and material supports available to them. Young children from birth to 8 years old, the period typically referred to as early childhood (Arnold, 2008), are likely to be the group most impacted by home environment characteristics (Richter, 2010). However, some researchers, including Irwin et al. (2009) in their work for the Joint Learning Initiative on Children and AIDS, show that welldesigned early childhood development (ECD) interventions can result in higher educational attainment and can counteract home factors that predict poor outcomes (Arnold, 2008; Martinez et al., 2012; Myers, 1992).

Given what the literature notes, we therefore focused our retrospective study on factors that can influence the age of school entry and grade level progression of children. We hypothesized that the most disadvantaged children, those who live in households with such life stresses as the absence of one or more parents or a personal connection to a disease such as HIV/AIDS, would be at greater risk of both enrolling in school later than the appropriate age (age 6, according to Uganda policy) and not advancing successfully. Additionally, we examined the influence of family variables and exposure to ECD services on the educational entry and transitions of young children.

\section{Context and Terms of our Study}

Data for the study were collected from 535 eight-year-old children and their primary athome caregivers in the peri-urban parish of Kyanja, near Kampala, the capital city of Uganda. The data presented in this report are based on the caregiver-reports component of this study. The home environment influences considered in the study include the effects of HIV/AIDS, family migration, parental separation, job losses, and deaths from various causes. We also examined the impact of ECD exposure, which included enrolment in ECD, age at enrolment, and category of ECD centre in which the children were enrolled, either formal or non-formal.

Formal ECD initiatives in this study refer to pre-school or pre-primary centres that mainly focus on school readiness (numeracy and literacy) for children aged 3 to 5 (Prochner \& Kabiru, 2008). Non-formal ECD initiatives are associated with the provision of care for children while caregivers work outside the home, but in the case of this study that care also included some 
International Journal of Child, Youth and Family Studies (2015) 6(4.1): 662-679

numeracy and literacy skill development along with social skills development, health and nutrition supports, and programs for parents. Non-formal ECD initiatives in Uganda are often operated by not-for-profit organizations, which is the case for this study. Indeed, all of the nonformal programs in Kyanja are operated by the non-profit organization Action for Children (AFC).

The home environment in this study refers to sociodemographic variables that are likely to be associated with the education and development of young children in the home, such as: Family structure (whether children live in families with both of their birth parents or in other arrangements that include living with a single parent, other family members, or caregivers not biologically related); age, gender, and education of the primary caregiver; total number of children in the home; number of orphans in the home; number of children aged 8 in the home; number of children in the home that are enrolled in ECD; number of children in primary school; the presence of HIV/AIDS in the household; divorce or separation of parents; family migration; loss of employment; death of parent(s); illness of parent(s); and lack of school fees. The term "primary caregiver" in this study refers to the person in the household who is engaged in providing the day-to-day care and nurturance of the child. These caregivers may include parents, grandparents, aunts, uncles, siblings, and other related individuals. A pictorial representation of the hypothesized relationships between the main variables included in this study is provided in Figure 1. On the left-hand side of this model are the sociodemographic characteristics of the child and the parent, and aspects of the home environment such as life circumstances (living with parent vs. not living with parent) and life stressors. At the intermediate level of this model is the child's exposure to early childhood education. The education outcome variables are shown at the right-hand side of this model.

\section{Method}

\section{Research Design}

Three quantitative research designs were considered before selecting the approach for this study: a cross-sectional study, a longitudinal panel study, and a retrospective study. These designs have varying advantages and disadvantages with reference to understanding child transitions in Kyanja parish. The design selected here was primarily a retrospective design, with some features adapted from longitudinal studies such as the Dunedin longitudinal study (e.g. Caspi et al., 2002). The Dunedin study utilized a community sample and a birth cohort, and obtained data from multiple reporting sources. The concept of combining a community study/ birth cohort strategy with a retrospective study led to a useful and efficient design. For example, when using a retrospective approach, all of the data can be obtained at once. Because the children participating were all of the same age (8 years old in this case), the need to modify questions according to age group or control for age in the data analyses is eliminated. The community sampling design can also address a large cohort, and makes it easy to obtain data from both children and caregivers. 
International Journal of Child, Youth and Family Studies (2015) 6(4.1): 662-679

Home environment

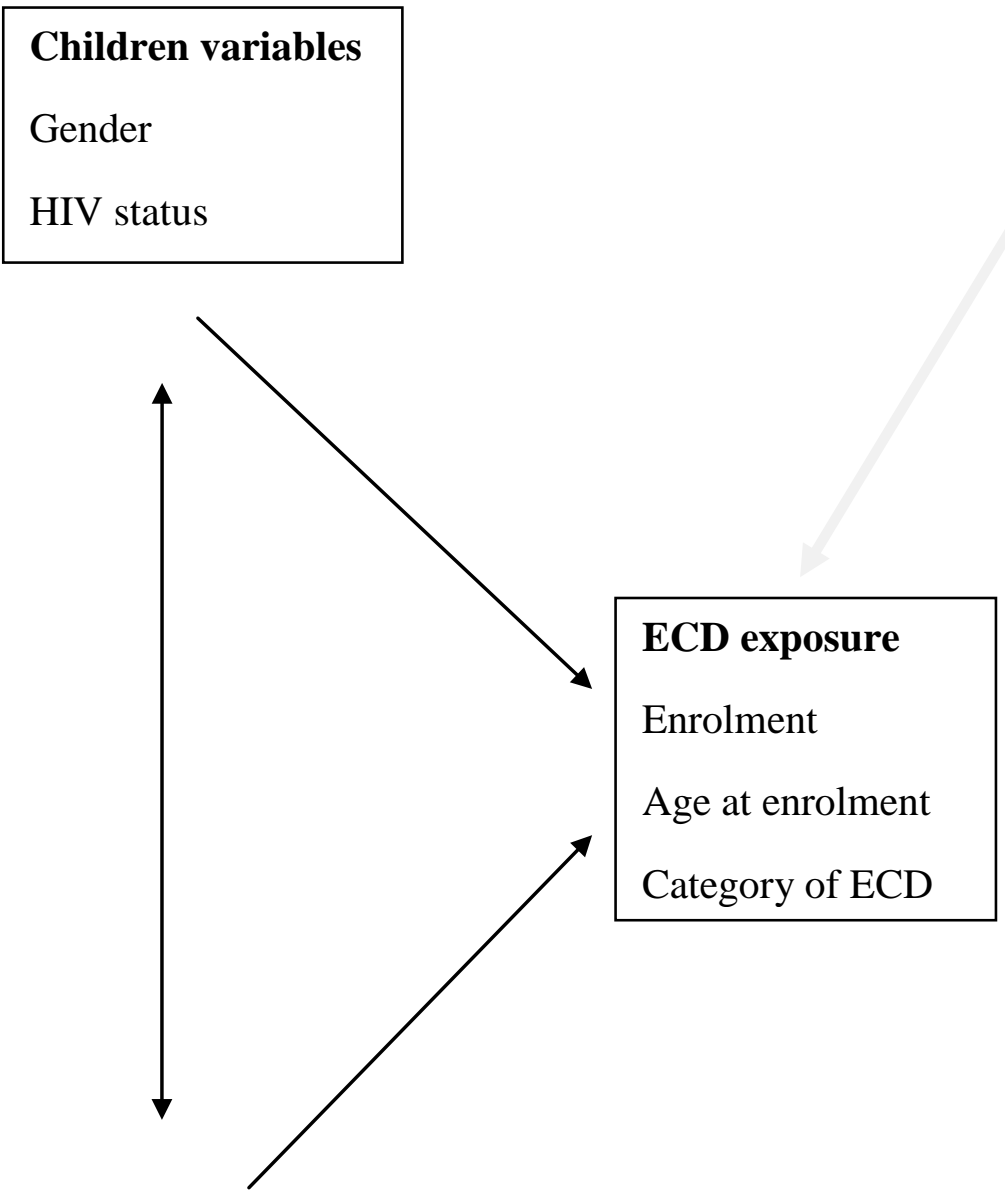

Caregiver variables

Age

Gender

Education level

Life stress events

$-. \cdot$
Education variables

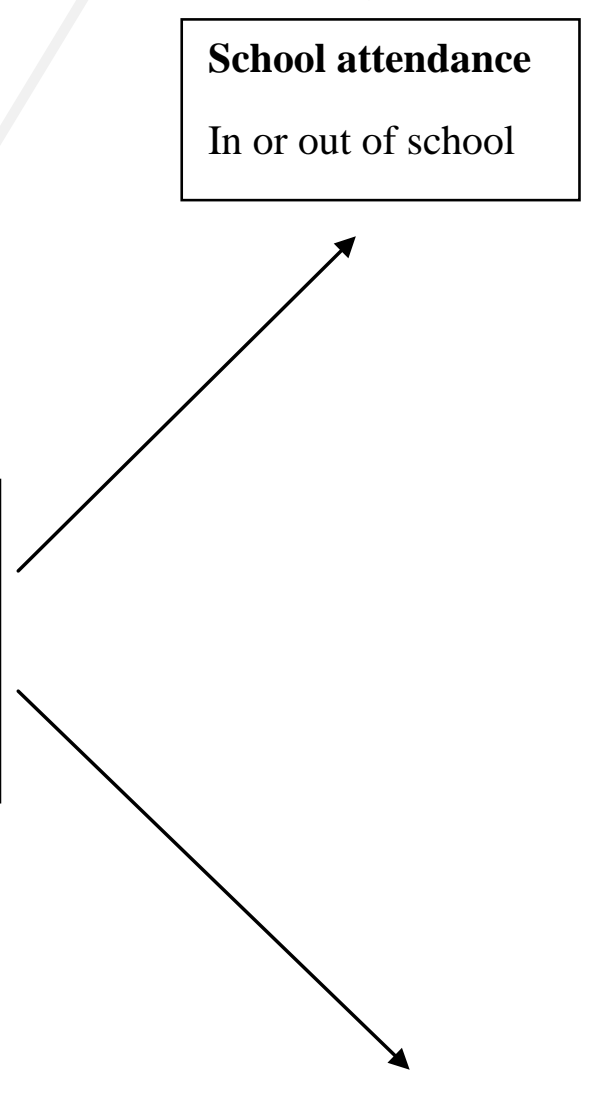

Grade in School

Figure 1. Sociodemographics, ECD exposure and school outcomes. 
International Journal of Child, Youth and Family Studies (2015) 6(4.1): 662-679

Retrospective study designs have been used before to obtain information on students' home environments in relation to their academic performance. For example, in a retrospective study of eighth graders and their family structure in the United States, Kurdek and Sinclair (1988) studied the school performance of 219 students with a mean age of 13.84 years (SD = 0.58). These researchers obtained information on students' end-of-year grades in relation to their home environment and found that students from two-parent nuclear families had higher end-ofyear grades than students in either mother-custody or stepfather families. Whereas Kurdek and Sinclair (1998) were interested in the performance of the children in terms of end-of-year grades, the current study interest is the progress of children in relation to enrolment, repetition, and grade promotion.

Further research showing the value of retrospective research is provided by Yancura and Aldwin (2009), whose well-designed retrospective assessments yield valuable data about childhood experiences. Retrospective research designs have also been found to be particularly useful for examining the link between adverse early childhood experiences and later outcomes (cf. Clarkson Freeman, 2014). However, researchers such as Yancura and Aldwin (2009) caution that retrospective self-reports can be influenced by individual characteristics such as age, gender, and physical health status. Retrospective accounts seem to work best when concrete information is being gathered, and reports are verified by using multiple response sources.

\section{Procedure}

After consultation with Kyanja parish officials, all households in the parish were visited to determine which households had children aged 8 years old. The children were from different home configurations, with $72 \%$ living with parents, $14 \%$ with grandparents, $13 \%$ with other relatives, and $1 \%$ with non-relatives. The households in which some of the children lived were affluent with regard to size, type, and location; others lived in low-income settings in which families of six or more might be crowded into dwellings of a single room. The study included children of 8 years of age regardless of whether these children had attended an ECD centre, and whether they attended primary school. Children who were unable to respond to the questions due to illness were excluded.

The primary caregivers were selected regardless of their relationship to the children. Both female and male primary caregivers were selected for interviews. The caregivers were asked about all children below 18 years old under their care in the home but the interview focused on the children who were 8 years old.

The data were obtained by interviewing respondents in person. The child interviews lasted approximately 30 minutes while the caregiver interviews lasted approximately one hour, or more if there were additional children in the household who were cared for by the same caregiver. The results in this report are based on the caregiver responses only. In each village of the parish, approximately 59 households were included in the study and a total of 1070 interviews with 535 children and 535 caregivers were obtained. Three households withdrew from the study after signing the consent form. The collected data were cleaned, removing incomplete questionnaires. 
International Journal of Child, Youth and Family Studies (2015) 6(4.1): 662-679

\section{Measures}

The data collection process used a structured interview based on an adapted version of the Home Screening Questionnaire (Richter \& Grieve, 1991; Brockington et al., 2001) derived from the Home Observation for Measurement of the Environment (HOME) scale (Bayley, 1969 quoted in Richter \& Grieve, 1991; Elardo \& Bradley, 1981) and adapted for South Africa by Richter and Grieve (1991) to gather historical data on children and their caregivers.

For the Richter and Grieve (1991) study, the Home Screening Questionnaire (HSQ) was translated from English into the local languages, Sizulu and Setswana, and back to English for cross-checking. The interviewers had to be language-flexible in the face of a multilingual South African community. While Richter and Grieve (1991) used the scale for infants, the HSQ was translated into local languages, giving an example of a translation into a local African language. The scale was adjusted to suit children of 8 years in the same way that Totsika and Sylva (2004) adjusted the HSQ to suit ages 3 to 6 years in their study on the early childhood home environment. In Kyanja, the common language of the community is Luganda, the native language spoken in the central region of Uganda. The questionnaire was translated by an expert translator into Luganda, and back-translation into English was employed to ensure that the content had survived translation intact. However, as Kyanja is semi-urban, some questionnaire forms in English were available for respondents who preferred them.

Through open and scaled (Likert) and closed (Yes/No) questions ,the interviews gathered details about the events that took place in the children's lives from birth to 8 years. The first page of the interview schedule contained instructions for the interviewer and for the respondents. The instructions were reminders extracted from the training for the researchers that was held three weeks before the survey. They included such items as being observant in case the respondent felt uncomfortable and wanted to stop the interview, and in case there were questions the child or caregiver felt uneasy about answering.

\section{Caregiver Interview}

The caregiver interview collected basic information on the demographics of the caregiver, the demographic and life circumstances of the child, the child's ECD involvement, and the child's entry and progress in the school system.

The caregiver demographic questions gathered information about: gender (male, female), highest education level $(1=$ no education, 2 = primary level, $3=$ secondary level, $4=$ postsecondary level), and relationship to the child ( 1 = parent, 2 = grandparent, 3 = elder sibling, $4=$ other).

The child demographic questions gathered information about the child's gender (male, female), who the child lived with (e.g., both parents, mother, father, grandparents, other), and age when they came to live in their current home (if not living at home with their parents).

The household life circumstances questions addressed the occurrence of parental loss for either one or both of the child's parents, and other family life stressors, including divorce of parents, separation of parents, remarriage of parents, destruction of the family home, family 
International Journal of Child, Youth and Family Studies (2015) 6(4.1): 662-679

migration, and loss of employment. When descriptive statistics showed that most of the children had suffered no stressors or only one stressor, a decision was made to construct a dichotomous variable with 0 being no stressor, and 1 being one or more stressors.

Further home environment questions addressed the possible effect of HIV/AIDS on the household. These questions were concerned with whether a child had lost a parent due to HIV/AIDS, whether a current family member was affected by HIV/AIDS, whether the child had been tested for HIV/AIDS, and whether results of this test had been positive.

The caregiver interview also addressed the child's involvement in ECD programs including the year of and age at ECD enrolment, time spent in ECD (less than 6 months, 6 months to 1 year, 1 year to 2 years, more than 2 years), and the type of ECD program. To determine the type of program, the respondent gave the name of the program, and the researchers, who were familiar with the programs, classified it as either formal or informal based on the proportion of structured activities included. The child's school progress was also addressed in the caregiver interview with questions concerning enrolment in school (yes, no), and current grade level (Primary 1, Primary 2, Primary 3, Primary 4).

If there was more than one 8-year-old child in the household, the caregiver answered the questions for each child and the responses were recorded on a separate form for each child.

\section{Data Analysis Strategy}

The study data analysis strategy involved three levels: descriptive, bivariate, and multivariate. In the descriptive analysis, frequencies for all of the variables used in the study were examined. The second level of analysis involved conducting bivariate analyses to determine if significant correlations existed between the home environment variables and ECD history, and the dependent variables, including school attendance and grade level in school.

In the third level of analysis, multivariate analyses were conducted to determine which variables predicted children's school attendance (not in school vs. in school) and the level of education attained (grade in school). For the first multivariate analyses, logistic regression was utilized to predict school entry versus non-entry. All of the significant caregiver variables that predicted school attendance in the bivariate analyses were included in this analysis. The order of entry for the predictor variables in this model was informed by the theoretical model shown in Figure 1. Sociodemographic and home environment predictors were entered first and the ECD exposure variable entered next. This order of entry allowed for the testing of a possible mediated relationship where some of the first-level predictors might be mediated through their influence on ECD exposure.

\section{Results}

The second multivariate analyses used linear regression to predict the grade level attained in school. The same strategy for selecting predictors and ordering the entry of variables that was employed in the previous model was also applied here. 
International Journal of Child, Youth and Family Studies (2015) 6(4.1): 662-679

To begin, we conducted a simple descriptive analysis of the children's and caregivers' demographic variables. There were 455 households with children aged 8 years old, but because there were some households with more than one child, the number of completed caregiver questionnaires was 535. The sample was composed of $n=449$ (83.9\%) female caregivers and $n=86$ (16.1\%) male caregivers, and $n=265$ (49.5\%) female children and $n=270$ (50.5\%) male children.

Out of the 535 caregiver responses received, 54 were taking care of two children each aged 8 years, 11 were caring for three children aged 8, and one respondent had five children aged 8 years of age. The rest of the respondents, $n=389$ (73\%), had one child aged 8 . Seventy two percent of the caregivers were aged below 40 years, 25\% were 40 to 60 years of age, and 3\% of the caregivers were above 60 years old.

\section{ECD Exposure}

According to caregiver reports, the number of children that had ever been enrolled in ECD was $n=512$ (95.7\%) compared to $n=23$ (4.3\%) who had never been enrolled. The caregiver reports indicated that the number of children that were enrolled in the formal ECD centres was $n=455$ (88.7\%) compared to $n=58$ (11.3\%) enrolled in the non-formal ECD centres operated by AFC.

\section{School Entry and Grade Level}

According to the caregiver reports, the majority of the children, $n=516$ (96.4\%), were in school, with the highest percentage of enrolments in Primary 2, $n=162$ (31.4\%), followed by Primary 3, $n=121$ (23.4\%). The rest of the children were enrolled in Primary $1, n=109$ (21.1\%), Primary 4, $n=65$ (12.6\%), and or were still in ECD, $n=43$ (8.3\%). An 8-year-old would normally be in Primary 3, but school grade results show that $60.9 \%$ of the children are below that grade, while $12.6 \%$ are above, either in Primary 4 or higher.

\section{Stressful Life Events}

Caregiver data indicated that $n=369$ (69.8\%) reported no known major stressful life events in the household, while $n=160$ (30.2\%) reported having a stressful life event in the household. This question was only asked of the caregivers. The type of stressful life events reported ranged from death of a parent, $n=55$ (10.3\%), to family migration, $n=47$ (8.8\%). Other stresses that were noted were divorce or separation, $n=14(2.6 \%)$, and loss of a job, $n=3$ $(0.3 \%)$.

Caregiver reports on family structure in the children's households revealed that $n=456$ (86\%) had both parents alive, while $n=18$ (3.4\%) had both parents dead. Others, $n=56$ (10.6\%), had one parent alive. The majority of the children lived with their birth parents, $\mathrm{n}=386$ (72.3\%), while others, $\mathrm{n}=79(14.8 \%)$ lived with grandparents, or in other arrangements. 
International Journal of Child, Youth and Family Studies (2015) 6(4.1): 662-679

\section{HIV/AIDS in the Household}

In relation to HIV/AIDS in the household, $n=504$ (95.1 \%) of the caregivers reported no presence of HIV/AIDS in the household, while $n=26$ (4.9\%) reported there was a person in the household with HIV/AIDS. The person reported to be with HIV/AIDS was usually a parent, $\mathrm{n}=13$ (39.4\%), followed by other people in the household, $\mathrm{n}=12$ (36.4\%). The siblings reported to be living with HIV/AIDS were $n=8$ (24.2\%). On whether the children had been tested or not for HIV/AIDS, the results showed that the majority, $n=474$ (89.4\%) had never been tested, while $n=56(10.6 \%)$ had been tested. Out of those tested, $n=48(85.7 \%)$ were found negative, while $n=8(14.3 \%)$ were positive. And of the children that tested positive, $n=6(75 \%)$ were receiving anti-retroviral treatment, while $n=2(25 \%)$ were not receiving the treatment.

\section{Correlation Results from the Caregiver Reports}

The correlation results based on the caregiver measures are presented in Table 1. This analysis showed that exposure to ECD was correlated with school attendance, $\mathrm{r}=.35(\mathrm{p} \leq .001)$, signifying that the children exposed to ECD were more likely to be in school. In addition, the children living with birth parents were more likely to be in formal ECD centres than non-formal centres. The caregiver education variable also correlated positively with formal ECD involvement, $\mathrm{r}=.15(\mathrm{p} \leq .001)$. Further, children who enrolled in ECD at an earlier age were more likely to be in higher grades than those who enrolled at a later age, $r=-.30(p \leq .001)$.

Table 1

Significant Correlations between Sociodemographic/Home Environment Variables and Children's Education Outcomes

\begin{tabular}{|c|c|c|c|c|c|c|c|c|c|}
\hline & 1 & 2 & 3 & 4 & 5 & 6 & 7 & 8 & $\overline{9}$ \\
\hline \multicolumn{10}{|l|}{ 1.ECD exposure } \\
\hline \multicolumn{10}{|l|}{ 2.Enrolment age } \\
\hline \multicolumn{10}{|l|}{ 3.ECD category } \\
\hline 4.School attend. & $-.35 * *$ & & & & & & & & \\
\hline 5.Grade & & $-.30 * *$ & & & & & & & \\
\hline 6.Caregiver age & & & $-.18 * *$ & & & & & & \\
\hline 7.Caregiver education & & & $.15^{* *}$ & $.12 * *$ & $.17 * *$ & & & & \\
\hline 8.Life stress & $-.18 * *$ & & & $-.18 * *$ & $-.16^{* *}$ & $.16^{* *}$ & $-.16^{* *}$ & & \\
\hline 9.Family structure & & & $.15^{* *}$ & & & $-.38 * *$ & & $-.28 * *$ & \\
\hline
\end{tabular}

** Correlation is significant at the 0.01 level (2-tailed).

The education level of the caregiver was found to be correlated with the children's school status enrolment, $r=12(p \leq .001)$, and grade level in school, $r=17(p \leq .001)$. 
International Journal of Child, Youth and Family Studies (2015) 6(4.1): 662-679

Stressful life events in the household were negatively correlated with school attendance, $r=-.18(p \leq .001)$. The households that reported the presence of a stressful life event were more likely to have children out of school. Similarly, stressful life events in households were negatively correlated with grade level, $r=-16(\mathrm{p} \leq .001)$. Children living in households that experienced stressful life events were more likely to be in lower grades, and not to have been exposed to ECD, as stressful life events were negatively correlated with exposure to ECD, $\mathrm{r}=$ $18(\mathrm{p} \leq .001)$.

\section{Regression Results from the Caregiver Reports}

In the first regression model, the technique of hierarchical logistic regression analysis was used to predict the dependent variable of school attendance $(0=$ not in school vs. $1=$ in school). The order of entry for the predictors in this model was informed by the theoretical model shown in Figure 1. The sociodemographic and home environment predictors, that is, family structure (both birth parents vs. other), education level of caregiver, and household stressful life events (not present vs. present) were entered in the first block, while ECD enrolment was added in the second block. The results of this analysis are shown in Table 2.

Table 2

Hierarchical Logistic Regression of Children's Home Environment Factors with School Status (Caregiver Reports)

\begin{tabular}{|c|c|c|c|c|}
\hline & \multicolumn{2}{|c|}{ Block 1} & \multicolumn{2}{|c|}{ Block 2} \\
\hline & OR & OR (95\% CI) & OR & OR (95\% CI) \\
\hline \multicolumn{5}{|c|}{$\begin{array}{l}\text { Caregiver Demographics/ } \\
\text { Home Environment }\end{array}$} \\
\hline Family structure & 1.30 & $(0.50-3.20)$ & 1.23 & $(0.45-3.36)$ \\
\hline Education level & $2.06^{*}$ & $(1.05-4.06)$ & $1.94 *$ & $(0.92-4.11)$ \\
\hline Life stress & $5.02 * *$ & $(1.83-13.74)$ & $3.53^{*}$ & $(1.21-10.31)$ \\
\hline \multicolumn{5}{|l|}{ ECD history } \\
\hline ECD exposure & & & \multicolumn{2}{|c|}{$.08 * * * \quad(0.03-.23)$} \\
\hline Model $\chi^{2}$ & 20.66 & & \multicolumn{2}{|l|}{38.68} \\
\hline Negelkerke $\mathrm{R}^{2}$ & .14 & & \multicolumn{2}{|l|}{.25} \\
\hline \multicolumn{5}{|l|}{${ }^{*} \mathrm{p} \leq .05 .{ }^{* *} \mathrm{p} \leq .01 .{ }^{* * *} \mathrm{p} \leq .001$} \\
\hline \multicolumn{5}{|c|}{$\begin{array}{l}\text { In the first step of this model, the sociodemographic domain predictors contributed } \\
\text { significantly in the prediction of school attendance }\left(\chi^{2}(3, N=529)=20.66, p<.001\right) \text {, and the } \\
\text { Nagelkerke } \mathrm{R}^{2} \text { statistic indicated that } 14 \% \text { of the variance in school grade level was explained. } \\
\text { The Hosmer and Lemeshow Goodness of Fit test indicated that the model adequately fit the data } \\
\left(\chi^{2}(6, N=529)=3.32, p<.77\right) \text {. }\end{array}$} \\
\hline
\end{tabular}


International Journal of Child, Youth and Family Studies (2015) 6(4.1): 662-679

Caregiver education level and household life stress were the two significant predictors of school enrolment. Children having more educated caregivers and lower household life stress levels were more likely to be attending school.

In the second step of the logistic regression analyses, the ECD enrolment predictors were added. This block of predictors contributed significantly to the model $\left(\chi^{2}(4, N=529)=18.03\right.$, $\mathrm{p}<.001$ ), with the Nagelkerke $\mathrm{R}^{2}$ statistic indicating that $25 \%$ of the variance was explained. The Hosmer and Lemeshow Goodness of Fit test indicated that the model adequately fit the data $\left(\chi^{2}(6, N=529)=6.82, p<.34\right)$. Caregiver education level remained a significant predictor and ECD enrolment was also significant. Specifically, school attendance was associated with higher caregiver education and ECD enrolment. The final model was significant $\left(\chi^{2}(4, N=529)=\right.$ $38.68, \mathrm{p}<.001$ ) with the Nagelkerke $\mathrm{R}^{2}$ showing that $25 \%$ of the variance was explained.

In the second regression model, hierarchical linear regression analyses were used to test the multivariate relationships between the predictors of family structure (intact with both biological parents vs. other), caregiver education level, household life stress, and grade level attained in school according to the caregivers' reports. This strategy allowed testing for possible mediated relationships. In this stage of analysis the significant predictors in the model, that is, family structure, education level of caregiver, and household life stress, were entered in the first block, while ECD exposure and age at enrolment were entered in the second block. The results of this analysis are presented in Table 3.

Table 3

Linear Regression of Children's Home Environment Factors with Grade in School (Caregiver Reports)

\begin{tabular}{lll}
\hline & $\begin{array}{l}\text { Block 1 } \\
\beta\end{array}$ & $\begin{array}{l}\text { Block 2 } \\
\beta\end{array}$ \\
\hline $\begin{array}{l}\text { Caregiver Demographics/ } \\
\text { Home Environment } \\
\text { Family structure }\end{array}$ & .05 & .03 \\
$\quad$ Education level & $.15^{* * *}$ & $.16^{* * *}$ \\
$\quad$ Life stress & $-.11^{*}$ & $-.13^{* *}$ \\
ECD exposure & & $-.30^{* * *}$ \\
$\quad$ Age at enrolment & & -.01 \\
ECD enrolment & & $.09^{* * *}$ \\
$\mathrm{R}^{2}$ Change & $.04^{* * *}$ & $.13^{* * *}$ \\
$\mathrm{R}^{2}$ Total & & \\
\hline
\end{tabular}

${ }^{*} \mathrm{p} \leq .05 .{ }^{* *} \mathrm{p} \leq .01 .{ }^{* * *} \mathrm{p} \leq .001$.

In the first block of the regression analysis, the sociodemographic and home environment predictors, that is, family structure and household life stress, only explained $4 \%$ of the variance. 
International Journal of Child, Youth and Family Studies (2015) 6(4.1): 662-679

The only significant predictor was the education level of the caregiver, $\beta=.15(\mathrm{p} \leq .001)$ and it explained $4.4 \%$ of the variance. When the second block of predictors was entered, an additional $9 \%$ of the variance was explained with caregiver education level remaining significant $\beta=.16$ $(\mathrm{p} \leq .01)$, and age at enrolment also significant $\beta=-.30(\mathrm{p} \leq .001)$. The higher the educational level of caregivers, and the earlier that children enrolled in ECD, the higher the grade level that was attained by the children involved. These predictors together explained $13 \%$ of the variance in the grade level attained.

\section{Discussion}

The major findings from this study are:

- $\quad$ Family structure is an important variable in predicting children's participation in ECD and school attendance.

- Educational level of caregivers is an important variable in predicting children's participation in ECD and school attendance.

- $\quad$ ECD history (attendance at ECD, age at ECD enrolment, and category of ECD) is significantly related to school attendance and grade level in school.

- Stressful life events in the household are significantly related to school attendance.

\section{Characteristics of Caregivers}

The educational attainments and life experiences of caregivers appear to play an important role when it comes to children's access to education. For the children who participated in this study, living with their biological parents was significantly correlated with both enrolling in ECD and entering primary school at an earlier age than children living with non-birth-parent caregivers. However, the education level of the caregiver, for both birth parents and non-birth parents, was also significantly correlated with access to ECD and achievement of a higher grade level in school for the children. Our study showed that the higher the education level of the caregiver, the greater the likelihood that the children were in school and in higher grades, while the reverse was also observed. This supports what we found in our review of previous research highlighting the important association of the level of education of caregivers with children's school enrolment and attendance (UNICEF, 2010; Irwin et al., 2009; Nampijja et al., 2010).

\section{ECD Attendance}

Our study also indicates that children who attended ECD were more likely to be in school than those who never attended ECD. This result is consistent with a number of studies in the majority (developing) world (Birgit, 2011; Engle, Dunkelberg, \& Issa, 2008; Fabian \& Dunlop, 2007; Bernard van Leer Foundation, 2006; Brown \& Biryetega, 2004; Njenga \& Kabiru, 2001), which found that ECD promotes or encourages children to enrol in school. Proponents of ECD attendance (Woodhead \& Moss, 2007; Garcia, Pence, \& Evans, 2008) assert that ECD creates a 
International Journal of Child, Youth and Family Studies (2015) 6(4.1): 662-679

bridge between home and school and can strongly influence children's enrolment in school. The positive contribution of ECD to school enrolment is made all the more apparent in our study by the finding that children who had attended ECD were more likely to be in school than children who were not exposed to ECD, despite the presence of stressful life events. This suggests that ECD enrolment is not only a bridge to further education but may well be a protective factor in the face of life stresses.

\section{Formal and Non-formal ECD}

This research has revealed that the majority of children in the study had been enrolled in formal ECD centres and that these children were in higher grade levels at school. This finding indicates that children who attended formal ECD centres had higher chances of enrolling in primary school and maintaining a progression to higher grades than did children attending nonformal ECD centres, although caregiver, family, and home factors interacted with these results.

\section{School Grade Level}

The study revealed that grade level was strongly predicted by ECD attendance. Children who had enrolled in ECD and had completed at least two years were in higher grades than those who did not.

While the results of this study have pointed to home environment stressors, parent education, and age at ECD enrolment as factors that predict school attendance and grade level, further research is needed to establish more factors influencing children's grade levels, such as the influence of poverty, which was not specifically addressed in this study.

\section{Age at Enrolment}

One of the study's findings is that children who enrolled in ECD at an early age, that is, at two or three years, (35\% of all participants), were more likely to be in higher grade levels. Enrolling early and staying longer, sometimes up to four years, was found to result in more consistent and larger positive effects on schooling participation and grade level.

\section{Stressful Life Events in the Household}

Stressful life events had a negative impact on children's enrolment in both ECD and school. The death of a parent had the strongest effect, and probably contributed most to the measured impact on the education of the children. It is also notable that parental death was most frequently from HIV/AIDS-related causes (25\%).

\section{HIV/AIDS}

While caregivers reported HIV/AIDS as a major cause of death in the households, the presence of HIV/AIDS in the households at the time of the study was low, with only $5 \%$ of households reporting its presence. In this study, we found no negative correlations between school enrolment, school progress, and HIV/AIDS. The findings of this study are not consistent 
International Journal of Child, Youth and Family Studies (2015) 6(4.1): 662-679

with assertions that children affected by HIV/AIDS have difficulty accessing educational services (Richter et al., 2006; Hunter \& Williamson, 1994), but confirms studies by UNICEF (2010) and Kasirye and Hisali (2009) who concluded that while in the past HIV/AIDS-affected children may have missed school, sub-Saharan Africa countries have made significant progress towards achieving consistent levels of school attendance. Instead, the presence of life stressors in general, not necessarily HIV/AIDS alone, was a stronger predictor of age at school enrolment. The reason may be that children in households facing stressful life events are more likely to be mobile, migrating from one household to another (Oleke, Blystad, Moland, Rekdal, \& Heggenhougen, 2006). Engle et al. (2007) assert that interventions for young children affected by HIV/AIDS, such as access to community-based child care and other forms of care, have not been rigorously assessed. Our study contributes to the research on access to ECD services and its effect on children's educational outcomes. It provides an assessment of ECD provision in lifestressed households directly affected by HIV/AIDS, and shows that ECD increases school attendance and progress even when dealing with HIV/AIDS.

\section{Strengths and Limitations of the Study}

One of the major strengths of this study is the very high participation rate achieved in the large sample of households. The study design and its implementation ensured that no 8-year-old child in the parish was left out.

There are, however, limitations to this study. First, the data were gathered only from participants that were found to be at home. The majority of the caregivers found at home were females as the males were often working outside the home. Moreover, the data set did not include other possible predictor demographic variables such as income and employment, nor were other issues considered such as culture, tribe, or ethnicity. The study did, however gather relevant sociodemographic data such as age, gender, and education level. Future research that integrates advanced multivariate inquiry would be beneficial to understanding the broader picture of caregiving, parenting, and education in relation to life stressors and socioeconomic challenges such as limitations in income.

Limited data are available on transitioning of children over time from home to ECD, to school, and within school (Athanasiou, 2006; Arnold et al., 2006). A longitudinal study that follows a cohort of children over time could provide a broader range of data with which to examine the relationships between the home environment and educational participation. Such data could expand the discussion of the impact of the home environment and life stressors on education.

Even though data were collected in only one peri-urban parish, it is believed to be representative of certain other parishes in Uganda, and can be applied to other similar settings. While the study has some limitations, they have minimal adverse effects on the findings. These limitations could be investigated in future research to augment and expand the kinds of studies so far undertaken and therefore help to build a larger, more diverse, and more relevant literature on the young child in Africa. 
International Journal of Child, Youth and Family Studies (2015) 6(4.1): 662-679

\section{Summary and Conclusion}

As noted in the opening of the Discussion section, our study showed the important contribution of the home environment to predicting a child's transition from home to ECD and to school. Further, our study has implications for government policies and priorities. Based on our findings we suggest that family-centred policies and programs that address the importance of early childhood development will improve children's well-being while reinforcing the home environment's capacity to deal with stressful life events. Interventions to promote ECD are costeffective investments to ensure that children are prepared for educational opportunities, thereby achieving the Millennium Development Goals of ensuring enrolment for both girls and boys (Engle et al., 2007; UNESCO, 2000). 
International Journal of Child, Youth and Family Studies (2015) 6(4.1): 662-679

\section{References}

Aidoo, A. A. (2008). Positioning ECD nationally: Trends in selected African countries. In M. Garcia, A. Pence, \& J. Evans (Eds.), Africa's Future, Africa's challenge: Early childhood care and development in Sub Saharan Africa, (pp. 29-48). Washington, DC: World Bank. http://dx.doi.org/10.1596/978-0-8213-6886-2

Arnold, C. (2008). Positioning ECCD in the $21^{\text {st }}$ Century. Coordinators Notebook, Issue 28. Toronto, ON: Consultative Group on Early Childhood Care and Development.

Arnold, C., Bartlett, K., Gowani, S., \& Merali R. (2006). Is everybody ready? Readiness, transition and continuity: Reflections and moving forward (Working Paper No. 41). The Hague, The Netherlands: Bernard van Leer Foundation and Aga Khan Foundation.

Athanasiou, M. S. (2006). It takes a village: Children's transition to kindergarten and school. Psychology Quarterly, 21(4), 468-473. http://dx.doi.org/10.1037/h0084133

Bernard van Leer Foundation. (2006). Annual Report. The Hague, The Netherlands: Author. Retrieved from http://www.bernardvanleer.org/Annual_Report_2006

Birgit, B. (2011). Social disparities in children's vocabulary in early childhood. Does preschool education help to close the gap? British Journal of Sociology, 62(1), 69-88. http://dx.doi.org/10.1111/j.1468-4446.2010.01345.x

Brockington, F., Oates, J., George, S., Turner, D., Vostanis, P., Sullivan, M., ... Murdoch, C. (2001). A screening questionnaire for mother-infant bonding disorders. Archives of Women's Mental Health, 3(4), 133-140. http://dx.doi.org/10.1007/s007370170010

Brown, C., \& Biryetega, A. (2004). Building resilience and a supportive environment: Childcentred approaches to HIV/AIDS (CCATH). Poster Exhibition: The XV International AIDS Conference, Bangkok, Thailand. London, UK: Health Link Worldwide.

Caspi, A., McClay. J., Moffitt, T. E., Mill, J., Martin, J. Craig, I. W., ... Poulton, R. (2002). Role of genotype in the cycle of violence in maltreated children. Science, 297, 851-854. http://dx.doi.org/10.1126/science.1072290

Clarkson Freeman, P. A. (2014). Prevalence and relationship between adverse childhood experiences and child behavior among young children. Infant Mental Health Journal, 35(6), 544-554. http://dx.doi.org/10.1002/imhj.21460

Elardo, R., \& Bradley, R. (1981). The home observation for measurement of the environment (HOME) scale: A review of research. Developmental Review, 1, 113-145. http://dx.doi.org/10.1016/0273-2297(81)90012-5

Engle, P. L., Black, M., Behrman, J., Cabral de Mello, M., Gertler, P., Kapiriri, L., ... Young, M. (2007). Strategies to avoid the loss of developmental potential in more than 200 million children in the developing world. The Lancet, 369(9557), 229-242. http://dx.doi.org/10.1016/s0140-6736(07)60112-3

Engle, P. L., Dunkelberg, E., \& Issa, S. (2008). ECD and HIV/AIDS: The newest programming and policy challenge. In M. Garcia, A. Pence, \& J. Evans (Eds.), Africa's Future, Africa's 
International Journal of Child, Youth and Family Studies (2015) 6(4.1): 662-679

challenge: Early childhood care and development in Sub Saharan Africa, (pp. 285-311). Washington, DC: World Bank. http://dx.doi.org/10.1596/978-0-8213-6886-2

Fabian, H., \& Dunlop, A. W. (2007). Outcomes of good practice in transition processes for children entering primary school (Working paper No. 42). The Hague, The Netherlands: Bernard van Leer Foundation. Retrieved from http://www.bernardvanleer.org

Garcia, M., Pence, A., \& Evans, J. (Eds.). (2008). Africa's Future, Africa's challenge: Early childhood care and development in Sub Saharan Africa. Washington, DC: World Bank. http://dx.doi.org/10.1596/978-0-8213-6886-2

Grantham-McGregor, S., Cheung, Y. B., Cueto, S., Glewwe, P., Richter, L., \& Strupp, B. (2007). Developmental potential in the first 5 years for children in developing countries. The Lancet,36(9555), 60-70. http://dx.doi.org/10.1016/s0140-6736(07)60032-4

Hunter, S., \& Williamson, J. (1994). Children on the brink. Washington, DC: USAID.

Irwin, A., Adams, A, \& Winter, A. (2009). Home truths: Facing the facts on children, AIDS, and poverty. Boston, MA: Joint Learning Initiative on Children and HIV/AIDS. Retrieved from http://www.ssrc.org/publications/view/home-truths-facing-the-facts-on-children-aids-andpoverty/

Kasirye, I., \& Hisali, E. (2009). The socioeconomic impact of HIV/AIDS on education outcomes in Uganda: School enrolment and the schooling gap in 2002/2003. International Journal of Educational Development, 30, 12-22. http://dx.doi.org/10.1016/j.ijedudev.2009.07.003

Kurdek, L., \& Sinclair, R. (1988). Relation of eighth graders' family structure, gender, and family environment with academic performance and school behavior. Journal of Educational Psychology, 80(1), 90-94. http://dx.doi.org/10.1037//0022-0663.80.1.90

Malmberg, L-E., Mwaura, P, \& Sylva, K. (2011). Effects of a preschool intervention on cognitive development among East-African preschool children: A flexibly time-coded growth model. Early Childhood Research Quarterly, 26, 124-133. http://dx.doi.org/10.1016/j.ecresq.2010.04.003

Martinez, S., Naudeau, S., \& Pereira, V. (2012). The promise of preschool in Africa: A randomized impact evaluation of early childhood development in rural Mozambique. Washington, DC: World Bank. Retrieved from http://www.savethechildren.org

Myers, R. (1992). The twelve who survive: Strengthening programmes of early childhood in developing countries. New York, NY: High Scope Press.

Nampijja, M., Apule, B., Lule, S., Akurut, H., Muhangi, L., Elliott, A. M., \& Alcock, K. J. (2010). Adaptation of western measures of cognition for assessing 5-year-old semi-urban Ugandan children. British Journal of Educational Psychology. 80, 15-30. http://dx.doi.org/10.1348/000709909x460600

Njenga, A., \& Kabiru, M. (2001). Early Childhood Development: Practice and Reflections. In the web of cultural transition: A tracer study of children in Embu district, Kenya. The Hague, The Netherlands: Bernard van Leer. Retrieved from http://www.bernardvanleer.org/In_the_web_of_cultural_transition 
International Journal of Child, Youth and Family Studies (2015) 6(4.1): 662-679

Oleke, C., Blystad, A., Moland, K. M., Rekdal, B. O., \& Heggenhougen, K. (2006). The varying vulnerability of African orphans: The case of the Langi, northern Uganda. Childhood 13(2), 267-284. http://dx.doi.org/10.1177/0907568206062943

Prochner, L., \& Kabiru, M. (2008). ECD in Africa: A historical perspective. In M. Garcia, A. Pence, \& J. Evans, (Eds.), Africa's Future, Africa's challenge: Early childhood care and development in Sub Saharan Africa, (pp. 117-130). Washington, DC: The World Bank. http://dx.doi.org/10.1596/978-0-8213-6886-2

Richter, L. (2010). Global perspectives on the well-being of children. In C. Worthman, P. Plotsky, D. Schechter, \& C. Cummings, (Eds.), Formative experiences: The interaction of caregiving, culture, and developmental psychobiology. New York, NY: Cambridge University Press. http://dx.doi.org/10.1017/cbo9780511711879

Richter, L., Foster, G., \& Sherr, L. (2006). Where the heart is: Meeting the psychosocial needs, orphan care, a challenge for policy makers. The Hague, The Netherlands: Bernard van Leer Foundation. http://www.bernardvanleer.org

Richter, L. \& Grieve, K. (1991). Home environment and cognitive development of black infants in impoverished South Africa families. Infant Mental Health Journal, 12(2), 88-102. http://dx.doi.org/10.1002/1097-0355(199122)12:2\%3C88::aid-imhj2280120202\%3E3.0.co;2-q

Totsika, V., \& Sylva, K. (2004). The home observation for measurement of the environment revisited. Child and Adolescent Mental Health, 9(1), 25-35. http://dx.doi.org/10.1046/j.1475-357x.2003.00073.x

UNESCO. (2000). The Dakar Framework for action. Education for all: Meeting our collective commitments. Adopted by the World Education Forum, Dakar, Senegal. April 26-28. Paris, France: Author.

UNICEF. (2010). Annual report. New York, NY: Author. Retrieved from http://www.unicef.org/publications/files/UNICEF_Annual_Report_2010_EN_052711.pdf

Walker, S., Wachs, T. D., Meeks-Gardner, J., Lozoff, B., Wasserman, G., Pollitt, E. ... the International Child Development Steering Group. (2007). Child development: Risk factors for adverse outcomes in developing countries. Lancet, 369, 145-157. http://dx.doi.org/10.1016/s0140-6736(07)60076-2

Woodhead, M. \& Moss, P. (Eds.). (2007). Early childhood and primary education: Transitions in the lives of young children. In M. Woodhead \& J. Oates (Series Eds.), Early childhood in focus. Vol. 2. Milton Heynes, UK: The Open University.

Yancura, L., \& Aldwin, C. (2009). Stability and change in retrospective reports of childhood experiences over a 5-year period: Findings from the Davis Longitudinal Study. Psychology and Aging, 24(3), 715-721. http://dx.doi.org/10.1037/a0016203 